\title{
Yucatan Micropig
}

National Cancer Institute

\section{Source}

National Cancer Institute. Yucatan Micropig. NCI Thesaurus. Code C91817.

A strain of Yucatan pig that weighs less than $55 \mathrm{~kg}$ when full grown. It was developed at Colorado State University in 1978 and is used extensively in biomedical research. 